\title{
Student's Perspectives on Augmented Reality in Pharmacy Education in Hong Kong
}

\author{
Joyce Tik Sze Li, Enoch E Nok Ng and Vivian Wing Yan Lee* \\ Centre for Learning Enhancement And Research, The Chinese University of Hong Kong, Hong Kong SAR, China
}

\section{OPEN ACCESS}

Edited by:

Fabrizio Consorti,

Sapienza University of Rome, Italy

Reviewed by:

Adamantios Koumpis,

University of Passau, Germany

Oscar Tamburis,

University of Naples Federico II, Italy

*Correspondence:

Vivian Wing Yan Lee

vivianlee@cuhk.edu.hk

Specialty section:

This article was submitted to

Digital Education,

a section of the journal

Frontiers in Education

Received: 11 August 2021 Accepted: 06 October 2021

Published: 21 October 2021

Citation:

Li JTS, Ng EEN and Lee WWY (2021)

Student's Perspectives on Augmented Reality in Pharmacy Education in

Hong Kong.

Front. Educ. 6:756907.

doi: 10.3389/feduc.2021.756907
Introduction: Augmented reality (AR) technology has demonstrated potential on various areas of healthcare practice. Its role on medical education is starting to emerge. This study aimed to investigate students' perspectives on using AR as learning tools in undergraduate pharmacy education.

Methods: Four AR micro modules on post-stroke management and chronic obstructive pulmonary disease (COPD) were developed for third year undergraduate pharmacy students to study. Students played the role of pharmacists in the AR micro modules. They collected information to identify patient's chief complaints, history, risk factors, comorbidities, and other problems, and provided recommendation on patient's treatment plans. Teacher guided the discussions and addressed student's enquiries. Student's feedback was collected by pre- and post-intervention survey.

Results: A total of 54 students participated in the current study. The was no significant change in students' perceived knowledge on post-stroke management and COPD, as well as their confidence in providing patient counselling on relevant topics. Students expressed that their learning experience with AR was not positive. Technical problems were the major difficulties that students encountered.

Conclusion: There was no significant difference in pharmacy students perceived clinical knowledge and confidence on patient's counselling after completing the AR modules. Technical issues were the major hurdles that hindered student's learning experience with AR.

Keywords: pharmacy education, augmented reality, pedagogy, active learning, practice experience

\section{INTRODUCTION}

As future healthcare professionals, pharmacy students must be equipped with knowledge and skills to provide patient-centred care in a team-based approach. (Zgheib et al., 2010; Miller et al., 2017; Lang et al., 2019) The Accreditation Council for Pharmacy Education emphasizes that pharmacy programs provide students with the knowledge, skills, and abilities to provide patient-centred care and solve problems. (Accreditation Council for Pharmacy Education, 2015) Practice experience is

Abbreviations: AR, Augmented reality; COPD, Chronic obstructive pulmonary disease; CUHK, The Chinese University of Hong Kong. 
essential for students to polish their communication skills and problem-solving skills. (Svensberg et al., 2018; Teramachi et al., 2018) Nevertheless, actual practice experience could be influenced by numerous factors, such as the availability of clinical sites, patient cases, and teaching staff. (Wartman, 2019; Shrestha et al., 2020) As information technology and communication technology advances, it is suggested that the challenges could be overcome by using simulated cases. (Okuda et al., 2009; Ray et al., 2012; Shin et al., 2015)

In recent years, augmented reality (AR) has demonstrated potential on various aspects in the medical field, including diagnosis, assessment, and treatment. (Freeman et al., 2017; Laver et al., 2017; Rothgangel et al., 2018; Chen et al., 2019; Feng et al., 2019) AR is an enhanced version of the real physical world that is achieved through the use of digital visual elements, sound, or other sensory stimuli delivered via technology. (Investopedia, 2020) One advantage of AR in medical education is the ability to visualize body tissues, for example, the skin, organs and muscles. (Sayadi et al., 2019; Yu et al., 2019; Siyar et al., 2020) Another advantage is that AR can repeat a simulated procedure as many times as desired, which is not practical in real patients or real environment. (Izard et al., 2018; Cao and Cerfolio, 2019) Pilot studies suggested that AR was a useful tool to create engaging and easy to use learning experiences in pharmacy education. (Salem et al., 2020; Schneider et al., 2020) Pharmacy students showed improvement in drug knowledge after completing the AR exercise and reported high usability and acceptability of AR for learning. (Salem et al., 2020; Schneider et al., 2020) AR technology can engage students into an active learning environment, which has been proven to be more effective than passive learning. (Ramnanan and Pound, 2017; Styers et al., 2018; Coyne et al., 2019) The technical capabilities of AR can support a learning-by-doing approach stressed by the constructivist learning principles. (Chen, 2010) They are also useful tools for delivering knowledge through embodied cognition, which emphasizes the interaction between learner and the environment. (Dunleavy and Dede, 2013) Nonetheless, AR is still considered as new technology in terms of pedagogy. They have not been widely adopted in the curriculum, and most teachers and students have limited experience of applying AR in education.

The current study aimed to investigate student's perspectives on using AR as learning tools in undergraduate pharmacy education.

\section{METHODS}

\section{Study Design and Study Population}

Our study population included third year undergraduate pharmacy students from the Chinese University of Hong Kong (CUHK) in 2018/2019 school year. Yearly, we admitted up to 60 pharmacy students. The pharmacy curriculum lasted for 4 years. In the first 2 years, students learnt the basic biological concepts and laboratory skills. In the third year, students had in-depth training on drug pharmacology and therapeutic uses. In the fourth year, students had clerkship training at clinical sites.
They needed to review patients' conditions and propose treatment plans for them independently. After graduation, they would receive internship training at workplaces for 1 year before registration.

The AR micro modules were used in the course "Clinical Assessment and Monitoring", which was a 3-units ( $3 \mathrm{~h}$ per week for a total of 13 weeks) compulsory course for third year pharmacy students at CUHK. It was a preparatory course prior to the clinical clerkship for the pharmacy students at the teaching hospital. This course involved classroom teaching on the theories on drug therapy assessment and therapeutic outcomes monitoring skills, as well as practicum in which students needed to apply previous knowledge on therapeutics to evaluate real patient cases in the teaching hospital. Upon completion of the course, students should be able to obtain medication-related information accurately, retrieve laboratory test results and vital signs, identify and utilise drug information resources to assist with patient-specific drug therapy monitoring, and present patient cases comprehensively.

Traditionally, learning activities of "Clinical Assessment and Monitoring" included lectures, discussion, medication chart review, and presentations. Teachers illustrated the technique of patient assessment by showing students some written case summaries, photos, and videos during lectures. Afterwards, students needed to review real patient cases, present the cases in class, and provide their recommendations. In the current study, four AR modules on post-stroke management and chronic obstructive pulmonary disease (COPD) were developed to illustrate clinical cases during lectures. These two topics were chosen for two major reasons. Firstly, pharmacology and therapeutics knowledge on COPD and stroke were covered in the course 'Pharmacology and Therapeutics I' (offered in year 2 semester 2) and 'Pharmacology and Therapeutics II' (offered in year 3 semester 1), respectively. Students taking the course 'Clinical Assessment and Monitoring' (offered in year 3 semester 2) should have adequate knowledge on the pharmacological management of COPD and stroke. Thus, the AR modules could focus on training students' drug therapy assessment skill and patient counselling skill. Conversely, if diseases covered in 'Pharmacology and Therapeutics III' (offered in year 3 semester 2) or 'Pharmacology and Therapeutics IV' (offered in year 4 semester 1) were chosen, extra time and effort would be needed to introduce the fundamental knowledge of disease management. Secondly, COPD and post-stroke management involved different pharmacist assessment skills, such as assessing disease control, inhaler technique, pharmacological and non-pharmacological treatment to improve patients' outcomes, etc. Previous students taking the same course often found them difficult to gather information and give advice when working on the real patient cases. The AR modules allowed students to practise their patient interview and counselling skills before working on the real cases.

\section{Materials}

Four AR micro modules on post-stroke management and COPD were launched. In each micro module, students were provided 


\section{Case background}

Mr. TM Chan, a 68-year-old male, reports that he has bad respiratory problem.

You are conducting a health interview with $\mathrm{Mr}$. Chan at a community outreach event. With further questions, you learn that he has been diagnosed with Chronic obstructive pulmonary disease (COPD) for more than 10 years. He reveals that he recently paid a visit to his family doctor for the flu and poor coughing. He shows you the medication bags with label. He claims that he is getting better with the medications. $\mathrm{He}$ asks for your comment and recommendation on whether he should keep getting the medications elsewhere.

A Case background

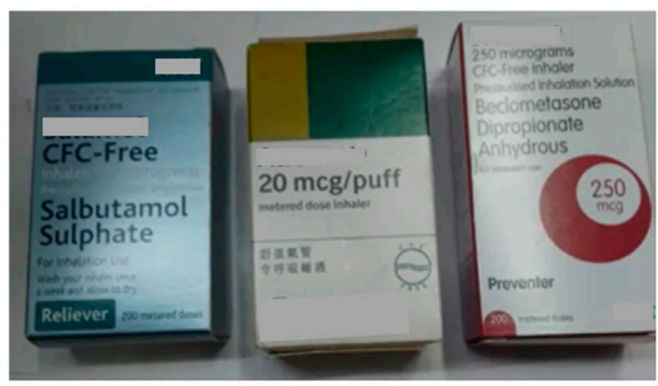

B Photo of patient's medications (Trigger image)

"The blue one, 4 times a day, 2 puffs each time. I have been using it for 10 years. The red one, twice per day, 2 puffs each time. I have tried my best to follow the instructions. But I sometimes forget to bring them with me when I'm out for work." TM Chan.

"I have a follow-up appointment next week and I will probably get a bunch of drugs. There are still a few unused inhalers at home. I think the drugs are not really useful." TM Chan.

\section{Script of the video clip (Overlay)}

FIGURE 1 | Content of a COPD micro module with case background, picture, and video script.

with a brief description of patient's case background and pictures showing hospital or clinic settings. Students needed to collect information on patient's chief complaint, past medical history, social history, current medications, and laboratory tests results in order to assess patient's disease control and recommend treatment plans. To collect the required information, students needed to use an AR scanning application, Layar, in their mobile device to scan and view the hidden items on each picture. The items included videos, audios, texts, and graphics. Students would be able to identify patient's chief complaints, history, risk factors, comorbidities, and other problems in the process. An example of COPD module was shown in Figure 1. A short paragraph describing the case background was first given to students. Then, students should scan the pictures (trigger images) located in different part of the classroom using Layar. By scanning a picture (trigger image) of an inhaled medication, students would get a video describing how the patient used the inhaler (overlay). By scanning a picture (trigger image) of a health questionnaire, students would get a patient interview audio describing patient's lifestyle, smoking habit, and sleep pattern (overlay). With the hidden information collected, students would be able to assess patient's condition and propose treatment plans.

In the classroom, students first worked on the AR cases individually, then discussed the clinical problems shown in the cases with their classmates and provided their recommendation on the treatment plans. The teacher guided the discussion, addressed student's questions, and provided feedback and suggestions to the proposed treatment plans.

\section{Statistical Analysis}

Pre- and post-self-evaluation surveys were used to assess the changes in students' knowledge on the relevant topics, evaluate the changes in their confidence on patient counselling, and collect feedbacks from students regarding their learning experience. Students were asked to rate, using Likert Scale of 1 (strongly disagree) to 5 (strongly agree), their self-perceived knowledge and confidence on COPD and post-stroke management in the preand post-survey. Data were presented as mean \pm standard deviation. The changes in student's score before and after engaging in AR learning activities were assessed by Wilcoxon signed-rank test. Statistically significance was defined as $p$-value $<$ 
TABLE 1 | Student's feedback on AR micro modules.

\begin{tabular}{|c|c|c|c|}
\hline Changes in students' knowledge & Pre-test $(n=50)$ & Post-test $(n=44)$ & $p$-value \\
\hline I am familiar with COPD. & $2.74 \pm 0.88$ & $2.80 \pm 0.85$ & $p=0.79$ \\
\hline I am familiar with post-stroke & $2.22 \pm 0.95$ & $2.55 \pm 0.87$ & $p=0.17$ \\
\hline \multicolumn{4}{|l|}{ Changes in students' confidence in patient counselling } \\
\hline I am confident to give a consultation to a COPD patient & $2.34 \pm 1.02$ & $2.55 \pm 0.98$ & $p=0.43$ \\
\hline I am confident to give a consultation to a post-stroke patient & $2.06 \pm 0.98$ & $2.43 \pm 0.97$ & $p=0.09$ \\
\hline Generally speaking, I am very confident with my patient consultation skills & $2.30 \pm 0.93$ & $2.61 \pm 0.89$ & $p=0.15$ \\
\hline \multicolumn{4}{|l|}{ Students' feedback } \\
\hline AR case studies can enhance my interest in learning certain disease topics & $3.40 \pm 0.83$ & $2.90 \pm 1.01$ & $p=0.06$ \\
\hline AR supports authentic learning & $3.48 \pm 0.71$ & $2.81 \pm 1.06$ & $p<0.01$ \\
\hline AR allows me to experience patient cases which would be impossible to generate in normal classroom environments & $3.56 \pm 0.81$ & $2.95 \pm 1.12$ & $p=0.01$ \\
\hline AR develops an immersive learning experience & $3.48 \pm 0.68$ & $2.84 \pm 1.06$ & $p<0.01$ \\
\hline I enjoy using AR as a learning tool & $3.24 \pm 0.85$ & $2.75 \pm 1.12$ & $p=0.02$ \\
\hline
\end{tabular}

AR: augmented reality; COPD: chronic obstructive pulmonary disease.

0.05. All statistical analyses were performed using IBM SPSS Statistics version 26. All students provided their written informed consent before participating in this study.

\section{RESULTS}

A total of 54 third year pharmacy students participated in the current study. There were 50 (92.59\%) and 44 (81.48\%) students who completed the pre-test and post-test respectively.

Table 1 summarized the changes in student's knowledge, confidence in patient counselling, and their learning experience with the AR micro modules. Students perceived that they were more familiar with COPD and post-stroke management, and were more confident with patient counselling. The changes were not statistically significant. However, students expressed negative feeling on their learning experience and gave lower scores in the post-test when asked whether they enjoyed using AR as learning tools and whether AR could support learning.

Students left both positive and negative comments on the survey. In general, students appreciated teacher's effort in designing the micro modules. They thought that the AR exercise could resemble real life practice, in which they needed to search for scattered patient information. One student wrote "I think it is good, since it is in outreach settings, some medical information about the patient cannot be obtained, and we have to analyze the case based on limited information, which is quite realistic." The major issue students raised was technical problem. A student wrote "Many of us cannot scan very well, especially in the lecture theatre." Another student wrote "Take too much time scanning, but actually can put the images online in advance." Some students though there was not a big difference between AR micro modules and their usual case study exercises.

\section{DISCUSSION}

In recent years, the scope of AR application has expanded, ranging from entertainment, urban planning, travelling, education, to healthcare. The use of $\mathrm{AR}$ in medical education has increased with the intention of achieving the potential benefits. One advantage is to make a patient case reproducible. (Izard et al., 2018; Cao and Cerfolio, 2019) In pharmacy education, AR exercises allow students to practise their drug therapy assessment skills and patient counselling skills anytime. (Fox and Felkey, 2017; Ventola, 2019) Previous studies had revealed an important benefit of virtual reality (VR) and AR exercises, which was to allow students to make mistakes while showing them the consequences of making a wrong decision. (Davidson et al., 2012; Nifakos et al., 2014) It could strengthen their memories on clinical knowledge and skills. Besides, VR and AR exercises allow each student to participate in the cases. In ward round settings, it is not feasible for each student to interview the same patient. VR and AR exercises can eliminate the time constraint and avoid disturbing the patient. (McGrath et al., 2018; Fealy et al., 2019) In addition, a teacher could run several simulated exercises at the same time, which further reduce the time constraint of teaching staff and students could gain more practice experience. (Caudell et al., 2003) Our study population, third year pharmacy students, had not started bedside learning. They did not have hands-on experience of reading case notes, taking patients history, or counselling patients. The AR exercises offered students the chance to practise and polish their skills before they entered clinical year and internship.

Despite the theoretical benefits that $\mathrm{AR}$ exercises can bring to medical education, studies have identified the limitations and problems in actual practice (Uruthiralingam and Rea, 2020). A systematic review by Gerup et al. analysed 26 studies involving AR or mixed reality in healthcare education. (Gerup et al., 2020) Gerup et al. pointed out the weaknesses of the studies, as well as the common difficulties with using AR as reported by the studies. (Gerup et al., 2020) One major problem identified was the inadequate evidence for improving learning. Studies were often designed as single group user studies, (Ma et al., 2016; Wang et al., 2016; Solbiati et al., 2018; Mewes et al., 2019) and many presented descriptive findings from self-reported evaluations without statistical analysis. (Sutherland et al., 2013; Bifulco et al., 2014; Ma et al., 2016; Wang et al., 2016; Kugelmann et al., 2018; Solbiati et al., 2018; Zhu et al., 2018; Mewes et al., 2019) This limited the 
generalisability of study results. Moreover, a portion of the studies reported no significant impact of AR on enhancing student's learning outcomes. (Moult et al., 2013; Moro et al., 2017; Noll et al., 2017; Rochlen et al., 2017; Siebert et al., 2017; Wang et al., 2017; Huang et al., 2018) Technological limitations were the common challenge reported among the studies. (Gerup et al., 2020)

In view of the conflicting results, there is a need to conduct a thorough assessment on how AR technology can facilitate student's learning, as well as evaluate student's perspectives on the new pedagogy. Our results echoed that reported in literature. Technical issues were the major problem that teachers and students encountered. Extra effort was needed to play an AR or VR video in usual classroom settings, as compared to a plain video. (Caudell et al., 2003; Samaniego Villarroel, 2016) For example, it took longer time for teachers to set up the devices in the classroom and for students to download the videos in their laptops. If the classrooms were not covered with stable network, it would take much more time for downloading the videos and graphics in class. In addition, playing AR or VR videos drained away the battery in the laptops quickly. It would be un-userfriendly if hardware supports were inadequate. As a result, student's learning experience was not positive. On the other hand, there was no significant difference in student's perceived knowledge and confidence with the topics. It might be because the AR exercises mainly simulated the patient interview and data collection process. Students evaluated their performance mainly through in-class discussion with peers and by listening to teacher's comments after class. Instant feedback from the AR exercises was limited. Thus, some students thought the learning objectives could be achieved by using conventional paper cases, which requires less preparation time and manpower.

With e-learning being more and more dominant in education, the prevalence of using AR in teaching is expected to grow. (Bacca et al., 2014; Lilly et al., 2019) Under the continued influence of Covid-19 pandemics, a lot of teaching activities such as practicum, clerkship, and clinical attachment had been called off. (Ahmed et al., 2020; Newman and Lattouf, 2020; Rajab et al., 2020; Singh et al., 2020) AR cases could provide alternative channels for students to learn. As technology advances, AR are getting more common in medical practice. (Li et al., 2017) It is expected that students will come across AR in their future careers. It would be beneficial for students to adapt to the technology during university study. Thus, the role of AR in the pharmacy curriculum should be further explored. Still, to ensure that AR technology can really add values to medical education, it is essential to define the learning objectives clearly and conduct structured evaluation on student's learning outcomes. Given that the time and financial cost required to produce an $\mathrm{AR}$ video are much longer than that of a plain video, it is crucial to select suitable topics when designing the teaching materials. Otherwise, AR exercises may not be cost-effective if the knowledge can be conveyed in a more straightforward way.

There are a few limitations in the study. Firstly, the impact of AR micro modules on student's learning was evaluated based on self-assessment. The cases were discussed in class to make sure students knew the right answers, but there was no specific quiz to formally assess the gain in knowledge among students. A more concrete relationship between the use of $A R$ and student's performance could be established if their examination results were compared. Secondly, the sample size of this study was limited by the class size of pharmacy department. Student's opinions and suggestions had been collected in the study. The tools should first be modified, then the survey can be repeated in the subsequent years to increase the sample size.

\section{CONCLUSION}

There was no significant difference in pharmacy students perceived clinical knowledge and confidence on patient's counselling after completing the AR modules. Technical issues were the major hurdles that hindered student's learning experience with AR.

\section{DATA AVAILABILITY STATEMENT}

The original contributions presented in the study are included in the article/supplementary material, further inquiries can be directed to the corresponding author.

\section{ETHICS STATEMENT}

The studies involving human participants were reviewed and approved by Survey and Behavioural Research Ethics Committee of the Chinese University of Hong Kong. Reference number: 14610518. The patients/participants provided their written informed consent to participate in this study.

\section{AUTHOR CONTRIBUTIONS}

All authors listed have made a substantial, direct, and intellectual contribution to the work and approved it for publication. JL analysed data and wrote the article, EN arranged the logistics and prepared teaching materials, VL contributed to the study design and supervised the study.

\section{FUNDING}

This study was funded by Teaching Development and Language Enhancement Grant for 2016-19 Triennium from The Chinese University of Hong Kong. The funding body had no role in the design of the study and collection, analysis, and interpretation of data and in writing the manuscript. 


\section{REFERENCES}

ACPE (2015). Accreditation Standards and Key Elements for the Professional Program in Pharmacy Leading to the Doctor of Pharmacy Degree. Available at https://www.acpe-accredit.org/standards/ (Accessed December 22, 2020)

Ahmed, H., Allaf, M., and Elghazaly, H. (2020). COVID-19 and Medical Education. Lancet Infect. Dis. 20 (7), 777-778. doi:10.1016/S1473-3099(20) 30226-7

Bacca, J., Baldiris, S., Fabregat, R., Graf, S., and Kinshuk (2014). Augmented Reality Trends in Education: A Systematic Review of Research and Applications. Educ. Techn. Soc. 17 (4), 133-149.

Bifulco, P., Narducci, F., Vertucci, R., Ambruosi, P., Cesarelli, M., and Romano, M. (2014). Telemedicine Supported by Augmented Reality: an Interactive Guide for Untrained People in Performing an ECG Test. Biomed. Eng. Online 13, 153. doi:10.1186/1475-925X-13-153

Cao, C., and Cerfolio, R. J. (2019). Virtual or Augmented Reality to Enhance Surgical Education and Surgical Planning. Thorac. Surg. Clin. 29 (3), 329-337. doi:10.1016/j.thorsurg.2019.03.010

Caudell, T. P., Summers, K. L., Holten, J., Hakamata, T., Mowafi, M., Jacobs, J., et al. (2003). Virtual Patient Simulator for Distributed Collaborative Medical Education. Anat. Rec. B New Anat. 270 (1), 23-29. doi:10.1002/ar.b.10007

Chen, C. J. (2010). Theoretical Bases for Using Virtual Reality in Education. Themes Sci. Techn. Educ. 2 (1-2), 71-90.

Chen, P. C., Gadepalli, K., MacDonald, R., Liu, Y., Kadowaki, S., Nagpal, K., et al. (2019). An Augmented Reality Microscope with Real-Time Artificial Intelligence Integration for Cancer Diagnosis. Nat. Med. 25 (9), 1453-1457. doi:10.1038/s41591-019-0539-7

Coyne, L., Merritt, T. A., Parmentier, B. L., Sharpton, R. A., and Takemoto, J. K. (2019). The Past, Present, and Future of Virtual Reality in Pharmacy Education. Am. J. Pharm. Educ. 83 (3), 7456. doi:10.5688/ajpe7456

Davidson, I. J., Lok, C., Dolmatch, B., Gallieni, M., Nolen, B., Pittiruti, M., et al. (2012). Virtual Reality: Emerging Role of Simulation Training in Vascular Access. Semin. Nephrol. 32 (6), 572-581. doi:10.1016/j.semnephrol.2012.10.009

Dunleavy, M., and Dede, C. (2013). "Augmented Reality Teaching and Learning," in Handbook of Research on Educational Communications and Technology. (New York, NY: Springer), 735-745.

Fealy, S., Jones, D., Hutton, A., Graham, K., McNeill, L., Sweet, L., et al. (2019). The Integration of Immersive Virtual Reality in Tertiary Nursing and Midwifery Education: A Scoping Review. Nurse Educ. Today 79, 14-19. doi:10.1016/ j.nedt.2019.05.002

Feng, H., Li, C., Liu, J., Wang, L., Ma, J., Li, G., et al. (2019). Virtual Reality Rehabilitation versus Conventional Physical Therapy for Improving Balance and Gait in Parkinson's Disease Patients: A Randomized Controlled Trial. Med. Sci. Monit. 25, 4186-4192. doi:10.12659/MSM.916455

Fox, B. I., and Felkey, B. G. (2017). Virtual Reality and Pharmacy: Opportunities and Challenges. Hosp. Pharm. 52 (2), 160-161. doi:10.1310/hpj5202-160

Freeman, D., Reeve, S., Robinson, A., Ehlers, A., Clark, D., Spanlang, B., et al. (2017). Virtual Reality in the Assessment, Understanding, and Treatment of Mental Health Disorders. Psychol. Med. 47 (14), 2393-2400. doi:10.1017/ S003329171700040X

Gerup, J., Soerensen, C. B., and Dieckmann, P. (2020). Augmented Reality and Mixed Reality for Healthcare Education beyond Surgery: an Integrative Review. Int. J. Med. Educ. 11, 1-18. doi:10.5116/ijme.5e01.ebla

Huang, C. Y., Thomas, J. B., Alismail, A., Cohen, A., Almutairi, W., Daher, N. S., et al. (2018). The Use of Augmented Reality Glasses in central Line Simulation: "see One, Simulate many, Do One Competently, and Teach Everyone". Adv. Med. Educ. Pract. 9, 357-363. doi:10.2147/AMEP.S160704

Investopedia (2020). Augmented Reality. Available at: https://www.investopedia. com/terms/a/augmented-reality.asp (Accessed Nov 4, 2020).

Izard, S. G., Juanes, J. A., García Peñalvo, F. J., Estella, J. M. G., Ledesma, M. J. S., and Ruisoto, P. (2018). Virtual Reality as an Educational and Training Tool for Medicine. J. Med. Syst. 42 (3), 50. doi:10.1007/s10916-018-0900-2

Kugelmann, D., Stratmann, L., Nühlen, N., Bork, F., Hoffmann, S., Samarbarksh, G., et al. (2018). An Augmented Reality Magic Mirror as Additive Teaching Device for Gross Anatomy. Ann. Anat. 215, 71-77. doi:10.1016/ j.aanat.2017.09.011
Lang, B., Zhang, L., Lin, Y., Han, L., Zhang, C., and Liu, Y. (2019). Team-based Learning Pedagogy Enhances the Quality of Chinese Pharmacy Education: a Systematic Review and Meta-Analysis. BMC Med. Educ. 19 (1), 286. doi:10.1186/s12909-019-1724-6

Laver, K. E., Lange, B., George, S., Deutsch, J. E., Saposnik, G., and Crotty, M. (2017). Virtual Reality for Stroke Rehabilitation. Cochrane Database Syst. Rev. 11 (11), CD008349. doi:10.1002/14651858.CD008349.pub4

Li, L., Yu, F., Shi, D., Shi, J., Tian, Z., Yang, J., et al. (2017). Application of Virtual Reality Technology in Clinical Medicine. Am. J. Transl. Res. 9 (9), 3867-3880.

Lilly, J., Kaneshiro, K. N., Misquith, C., and Dennett, B. (2019). Creating a New "reality" for Medical Education: the Nexus Reality Lab for Virtual Reality. J. Med. Libr. Assoc. 107 (4), 609-610. doi:10.5195/jmla.2019.784

Ma, M., Fallavollita, P., Seelbach, I., Von Der Heide, A. M., Euler, E., Waschke, J., et al. (2016). Personalized Augmented Reality for Anatomy Education. Clin. Anat. 29 (4), 446-453. doi:10.1002/ca.22675

McGrath, J. L., Taekman, J. M., Dev, P., Danforth, D. R., Mohan, D., Kman, N., et al. (2018). Using Virtual Reality Simulation Environments to Assess Competence for Emergency Medicine Learners. Acad. Emerg. Med. 25 (2), 186-195. doi:10.1111/acem.13308

Mewes, A., Heinrich, F., Kägebein, U., Hensen, B., Wacker, F., and Hansen, C. (2019). Projector-based Augmented Reality System for Interventional Visualization inside MRI Scanners. Int. J. Med. Robot. 15 (1), e1950. doi:10.1002/rcs.1950

Miller, D. M., Khalil, K., Iskaros, O., and Van Amburgh, J. A. (2017). Professional and Pre-professional Pharmacy Students' Perceptions of Team Based Learning (TBL) at a Private Research-Intensive university. Curr. Pharm. Teach. Learn. 9 (4), 666-670. doi:10.1016/j.cptl.2017.03.001

Moro, C., Štromberga, Z., Raikos, A., and Stirling, A. (2017). The Effectiveness of Virtual and Augmented Reality in Health Sciences and Medical Anatomy. Anat. Sci. Educ. 10 (6), 549-559. doi:10.1002/ase.1696

Moult, E., Ungi, T., Welch, M., Lu, J., McGraw, R. C., and Fichtinger, G. (2013). Ultrasound-guided Facet Joint Injection Training Using Perk Tutor. Int. J. Comput. Assist. Radiol. Surg. 8 (5), 831-836. doi:10.1007/s11548-0120811-5

Newman, N. A., and Lattouf, O. M. (2020). Coalition for Medical Education-A Call to Action: A Proposition to Adapt Clinical Medical Education to Meet the Needs of Students and Other Healthcare Learners during COVID-19. J. Card. Surg. 35 (6), 1174-1175. doi:10.1111/jocs.14590

Nifakos, S., Tomson, T., and Zary, N. (2014). Combining Physical and Virtual Contexts through Augmented Reality: Design and Evaluation of a Prototype Using a Drug Box as a Marker for Antibiotic Training. PeerJ 2, e697. doi:10.7717/peerj.697

Noll, C., von Jan, U., Raap, U., and Albrecht, U. V. (2017). Mobile Augmented Reality as a Feature for Self-Oriented, Blended Learning in Medicine: Randomized Controlled Trial. JMIR Mhealth Uhealth 5 (9), e139. doi:10.2196/mhealth.7943

Okuda, Y., Bryson, E. O., DeMaria, S., Jr, Jacobson, L., Quinones, J., Shen, B., et al. (2009). The Utility of Simulation in Medical Education: what Is the Evidence? Mt Sinai J. Med. 76 (4), 330-343. doi:10.1002/msj.20127

Rajab, M. H., Gazal, A. M., and Alkattan, K. (2020). Challenges to Online Medical Education during the COVID-19 Pandemic. Cureus 12 (7), e8966. doi:10.7759/ cureus. 8966

Ramnanan, C. J., and Pound, L. D. (2017). Advances in Medical Education and Practice: Student Perceptions of the Flipped Classroom. Adv. Med. Educ. Pract. 8, 63-73. doi:10.2147/AMEP.S109037

Ray, S. M., Wylie, D. R., Shaun Rowe, A., Heidel, E., and Franks, A. S. (2012). Pharmacy Student Knowledge Retention after Completing Either a Simulated or Written Patient Case. Am. J. Pharm. Educ. 76 (5), 86. doi:10.5688/ajpe76586

Rochlen, L. R., Levine, R., and Tait, A. R. (2017). First-Person Point-of-ViewAugmented Reality for Central Line Insertion Training: A Usability and Feasibility Study. Simul. Healthc. 12 (1), 57-62. doi:10.1097/ SIH.0000000000000185

Rothgangel, A., Braun, S., Winkens, B., Beurskens, A., and Smeets, R. (2018). Traditional and Augmented Reality Mirror Therapy for Patients with Chronic Phantom Limb Pain (PACT Study): Results of a Three-Group, Multicentre Single-Blind Randomized Controlled Trial. Clin. Rehabil. 32 (12), 1591-1608. doi:10.1177/0269215518785948 
Salem, S., Cooper, J., Schneider, J., Croft, H., and Munro, I. (2020). Student Acceptance of Using Augmented Reality Applications for Learning in Pharmacy: A Pilot Study. Pharmacy (Basel) 8 (3), 122. doi:10.3390/ pharmacy8030122

Samaniego Villarroel, J. C. (2016). Realidad Virtual en la Educación el Próximo Desafío. Jsr 1 (CITT2016), 57-61. doi:10.26910/issn.2528-8083

Sayadi, L. R., Naides, A., Eng, M., Fijany, A., Chopan, M., Sayadi, J. J., et al. (2019). The New Frontier: A Review of Augmented Reality and Virtual Reality in Plastic Surgery. Aesthet. Surg. J. 39 (9), 1007-1016. doi:10.1093/ asj/sjz043

Schneider, J., Patfield, M., Croft, H., Salem, S., and Munro, I. (2020). Introducing Augmented Reality Technology to Enhance Learning in Pharmacy Education: A Pilot Study. Pharmacy (Basel) 8 (3), 109. doi:10.3390/pharmacy8030109

Shin, S., Park, J. H., and Kim, J. H. (2015). Effectiveness of Patient Simulation in Nursing Education: Meta-Analysis. Nurse Educ. Today 35 (1), 176-182. doi:10.1016/j.nedt.2014.09.009

Shrestha, S., Shakya, D., and Palaian, S. (2020). Clinical Pharmacy Education and Practice in Nepal: A Glimpse into Present Challenges and Potential Solutions. Adv. Med. Educ. Pract. 11, 541-548. doi:10.2147/AMEP.S257351

Siebert, J. N., Ehrler, F., Gervaix, A., Haddad, K., Lacroix, L., Schrurs, P., et al. (2017). Adherence to AHA Guidelines when Adapted for Augmented Reality Glasses for Assisted Pediatric Cardiopulmonary Resuscitation: A Randomized Controlled Trial. J. Med. Internet Res. 19 (5), e183. doi:10.2196/jmir.7379

Singh, K., Srivastav, S., Bhardwaj, A., Dixit, A., and Misra, S. (2020). Medical Education during the COVID-19 Pandemic: A Single Institution Experience. Indian Pediatr. 57 (7), 678-679. doi:10.1007/s13312-020-1899-2

Siyar, S., Azarnoush, H., Rashidi, S., and Del Maestro, R. F. (2020). Tremor Assessment during Virtual Reality Brain Tumor Resection. J. Surg. Educ. 77 (3), 643-651. doi:10.1016/j.jsurg.2019.11.011

Solbiati, M., Passera, K. M., Rotilio, A., Oliva, F., Marre, I., Goldberg, S. N., et al. (2018). Augmented Reality for Interventional Oncology: Proof-Of-Concept Study of a Novel High-End Guidance System Platform. Eur. Radiol. Exp. 2, 18. doi:10.1186/s41747-018-0054-5

Styers, M. L., Van Zandt, P. A., and Hayden, K. L. (2018). Active Learning in Flipped Life Science Courses Promotes Development of Critical Thinking Skills. CBE Life Sci. Educ. 17 (3), ar39. doi:10.1187/cbe.16-11-0332

Sutherland, C., Hashtrudi-Zaad, K., Sellens, R., Abolmaesumi, P., and Mousavi, P. (2013). An Augmented Reality Haptic Training Simulator for Spinal Needle Procedures. IEEE Trans. Biomed. Eng. 60 (11), 3009-3018. doi:10.1109/ TBME.2012.2236091

Svensberg, K., Sporrong, S. K., Lupattelli, A., Olsson, E., Wallman, A., and Björnsdottir, I. (2018). Nordic Pharmacy Students' Opinions of Their Patient Communication Skills Training. Am. J. Pharm. Educ. 82 (2), 6208. doi:10.5688/ajpe6208
Teramachi, H., Ino, Y., Sugita, I., Nishio, Y., Yoshida, A., Hayashi, Y., et al. (2018). Evaluating Communication Skills after Long-Term Practical Training Among Japanese Pharmacy Students. Curr. Pharm. Teach. Learn. 10 (4), 446-452. doi:10.1016/j.cptl.2017.12.006

Uruthiralingam, U., and Rea, P. M. (2020). Augmented and Virtual Reality in Anatomical Education - A Systematic Review. Adv. Exp. Med. Biol. 1235, 89-101. doi:10.1007/978-3-030-37639-0_5

Ventola, C. L. (2019). Virtual Reality in Pharmacy: Opportunities for Clinical, Research, and Educational Applications. PT 44 (5), 267-276.

Wang, L. L., Wu, H. H., Bilici, N., and Tenney-Soeiro, R. (2016). Gunner Goggles: Implementing Augmented Reality into Medical Education. Stud. Health Technol. Inform. 220, 446-449.

Wang, S., Parsons, M., Stone-McLean, J., Rogers, P., Boyd, S., Hoover, K., et al. (2017). Augmented Reality as a Telemedicine Platform for Remote Procedural Training. Sensors (Basel) 17 (10), 2294. doi:10.3390/s17102294

Wartman, S. A. (2019). The Empirical Challenge of 21st-Century Medical Education. Acad. Med. 94 (10), 1412-1415. doi:10.1097/ACM.0000000000002866

Yu, X., Xie, Z., Yu, Y., Lee, J., Vazquez-Guardado, A., Luan, H., et al. (2019). Skinintegrated Wireless Haptic Interfaces for Virtual and Augmented Reality. Nature 575 (7783), 473-479. doi:10.1038/s41586-019-1687-0

Zgheib, N. K., Simaan, J. A., and Sabra, R. (2010). Using Team-Based Learning to Teach Pharmacology to Second Year Medical Students Improves Student Performance. Med. Teach. 32 (2), 130-135. doi:10.3109/01421590903548521

Zhu, E., Fors, U., and Smedberg, A. (2018). Exploring the Needs and Possibilities of Physicians' Continuing Professional Development - an Explorative Qualitative Study in a Chinese Primary Care Context. PloS one 13 (8), e0202635. doi:10.1371/journal.pone.0202635

Conflict of Interest: The authors declare that the research was conducted in the absence of any commercial or financial relationships that could be construed as a potential conflict of interest.

Publisher's Note: All claims expressed in this article are solely those of the authors and do not necessarily represent those of their affiliated organizations, or those of the publisher, the editors and the reviewers. Any product that may be evaluated in this article, or claim that may be made by its manufacturer, is not guaranteed or endorsed by the publisher.

Copyright $\odot 2021 \mathrm{Li}, \mathrm{Ng}$ and Lee. This is an open-access article distributed under the terms of the Creative Commons Attribution License (CC BY). The use, distribution or reproduction in other forums is permitted, provided the original author(s) and the copyright owner(s) are credited and that the original publication in this journal is cited, in accordance with accepted academic practice. No use, distribution or reproduction is permitted which does not comply with these terms. 